\title{
Hvordan
}

\section{bnei menashe \\ ble en minoritet i Israel}

Siden 1990-årene har indere immigrert til Israel takket være jødiske og evangelikalske interessegrupper. Nå utgjør de en minoritet på rundt 3000 personer, hvorav mange er bosatt i konfliktfylte områder.

Av Silje Belghaug Knarud og Hanne Amanda Trangerud, mastere i religionshistorie ved Universitetet i Oslo.

$\mathrm{I}^{2}$

2003 HJALP DEN JøDISKE SIONISTORGANISAsjonen Shavei Israel 80 indere med å bosette seg i Shavei Shomron, nær den palestinske byen Nablus på Vestbredden. ${ }^{1}$ Til da hadde rundt 1500 indere gjort aliyah (et begrep som brukes om jødisk migrasjon til Israel). Mange hadde fått sine nye hjem i andre jødiske bosetninger nær Hebron og på Gazastripen. Inderne hevdet å være av israelittisk herkomst, og immigrasjonen ble sett på som en tilbakevending til deres opprinnelige hjemland.

Juni 2003 satte innenriksminister Avraham Poraz fra det liberale sionistpartiet Shinui foten ned for migrasjonsprosjektet. Poraz stilte spørsmål ved indernes jødiske tilhørighet, og hevdet prosjektet var et politisk middel for å styrke ekstremistiske bosetninger i konfliktfylte områder. ${ }^{2}$ Lederen for Shavei Israel, Michael Freund, forsvarte prosjektet med at Israel burde tenke mer kreativt for å øke den jødiske befolkningen i stedet for å gi slipp på landområder. ${ }^{3}$ Da immigrasjonen av nye indere stanset, la jødiske og evangelikalske interessegrupper press på israelske politikere.
Lobbyvirksomheten ga resultater: I 2005 ble grensene igjen åpnet for stammefolket fra Nordøst-India.

I denne artikkelen ser vi nærmere på mytene som ligger til grunn for prosjektet som har skapt en indisk minoritet i Israel. Med myter mener vi her tradisjonsfortellinger som bidrar til å skape identitet, tilhørighet og handling. Vi tar ikke stilling til sannhetsinnholdet i disse mytene, men ser i stedet på samspillet som mytene skaper mellom svært ulike grupper i skjæringspunktet mellom religion og politikk.

Vi vil se på tre relaterte myter og hvordan disse utspiller seg historisk og sosiopolitisk. Først presenterer vi identitetsmyten til de indiske immigrantene. Deres fortelling handler om røtter som strekker seg 2700 år tilbake i tid, da ti av de tolv israelittiske stammene ble ført bort fra sine landområder av assyrerne. Under navnet bnei menashe - «Manasses sønner» -

«Den 18. juni 2015 landet de første 78 av 250 Bnei Menashe på Ben Gurion, og kunne ikke skjule gleden sin.» Fra Shavei Israels Flickrside. 


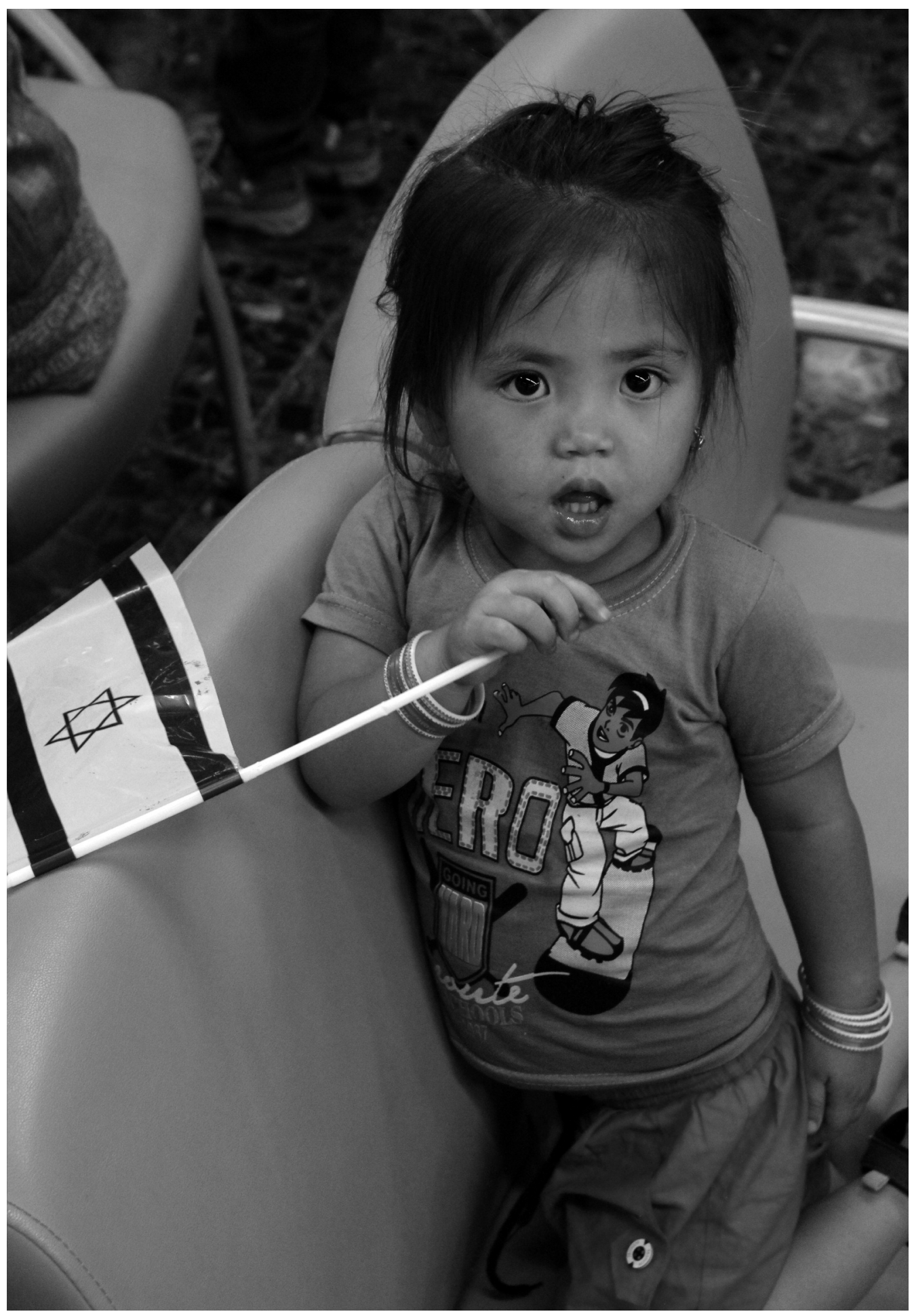




\section{SILJE BELGHAUG KNARUD G HANNE AMANDA TRANGERUD}

hevder disse inderne nå å være etterkommere av en av Israels ti tapte stammer.

Deretter ser vi på det vi har kalt den jødiske legitimeringsmyten. Denne utgjør rammefortellingen for bnei menashes identitetsmyte, og fungerer som en viktig legitimering av jødiske organisasjoners arbeid for å bringe «skjulte og tapte jøder» til Israel.

Den siste myten vi ser på, er den evangelikalske, eller kristensionistiske. Det som skiller denne myten fra de andre, er at den utspiller seg i en kristen eskatologisk kontekst. Kristensionistene bygger videre på den jødiske rammefortellingen, og anser tilbakeføringen av jøder til Israel som avgjørende for verdens frelse.

Som vi skal se, er samtlige tre myter nødvendige for at den indiske immigrasjonen til Israel kan finne sted. Mytene har også vist seg å ha innvirkning på politiske beslutninger på nasjonalt og internasjonalt nivå. Er dette migrasjonsprosjektet et uttrykk for religiøs overbevisning, eller er det bedre karakterisert som et strategisk spill i en territoriell konflikt?

\section{Bnei menashe - en identitetsmyte}

Gruppen som går under navnet bnei menashe kommer fra ulike stammefolk i Nordøst-India og Myanmar. Fra begynnelsen av 1900-tallet ble kristendom dominerende i området takket være protestantiske misjonærers virksomhet blant stammefolkene som da var animister. I dag preger kristen identitet store deler av dagliglivet. De praktiserende jødene utgjør kun en liten brøkdel av stammene. ${ }^{4}$ Litt over 3000 medlemmer av bnei menashe er bosatt i Israel, mens anslagsvis 7200 venter på å få gjøre aliyah. 5

Ideen om bnei menashe og en jødisk identitet oppsto på 1950-tallet. Ifølge beretningen mottok pinsevennpastoren Tchalah et budskap fra Gud om at hans folk måtte vende tilbake til sin opprinnelige religion og sitt opprinnelige land. ${ }^{6}$ Siden den gang har bnei menashes identitetsmyte også gitt opphav til personlige myter. En talende illustrasjon er den 28 år gamle lærerinnen Chongs uttalelse til avisa The Jerusalem Post, mens hun forberedte seg på å gjøre aliyah i den indiske byen Churachandpur:

My great-grandmother would tell my grandmother, 'We do not belong here, we belong in Zion, will go there on an iron bird.' My grandmother then told my mother the same thing, 'We are Bnei Menashe, we do not belong here, we belong in Zion, we will go to Zion on an iron bird.' I mean, this is crazy, what is an iron bird? But now we know and it's a miracle, we're seeing it in our time. We know an iron bird is an airplane, and we are going to Zion.»"

Medlemmene av bnei menashe knytter sin identitet til myten om Israels ti tapte stammer. Stammenes eksistens har gjennom historien vært omdiskutert. Selv om de antas å ha blitt assimilert med andre folkegrupper, er få detaljer kjent. Likevel hevder nå etniske minoriteter verden over at de er deres etterkommere.

Beretningen om de ti stammene ender brått i Bibelen etter at assyrerne erobrer Nord-Riket Israel og fører folket vekk fra landet. ${ }^{8}$ Det gamle testamentet forteller at stammene som bodde i Nord-Riket hadde vært ulydige overfor Gud, og deres eksil blir av jødiske lærde ansett som Guds straff. ${ }^{9}$ Likevel skulle ikke stammene være borte for alltid, ifølge bibeltekstene; profetene predikerte at deres etterkommere ville returnere til landet, forløst fra sine synder, og bli gjenforent med sine «søskenstammer". ${ }^{10}$

Ifølge myten om bnei menashes historie, skal deres forfedre ha flyktet fra assyrernes fangenskap til Afghanistan og videre til Kaifeng i Kina i 240 fvt., hvor de skal ha blitt holdt som slaver. 
Her skal mange av dem ha blitt drept eller assimilert, noe som førte til at israelittene flyktet og gjemte seg i huler. I år 100 evt. skal de ha blitt kastet ut av Kaifeng, mens deres skriftlige kilder ble brent og ødelagt. Ifølge myten ble så gruppen splittet og spredt over store deler av Sørøst-Asia, hvor de har levd siden. ${ }^{11}$ Etter at kristne misjonærer på 1950-tallet fattet interesse for gruppen som en "tapt stamme», har medlemmene av bnei menashe fått en israelittisk identitetsfølelse, og hevder sin rett til å «vende tilbake» til Israel.

I 1997 sendte lederne for bnei menashe en forespørsel til Israels statsminister Benjamin Netanyahu (1996-99) om å få «komme hjem». Brevet ble lest av Michael Freund, en amerikansk jøde som hadde immigrert til Israel, og som tjenestegjorde ved statsministerens kontor. Forespørselen inspirerte Freund til å opprette Shavei Israel, en organisasjon som søker å bringe "tapte og skjulte jøder» tilbake til Israel, herunder samtlige medlemmer av bnei menashe. ${ }^{12}$

Siden oppstarten på 9o-tallet har Shavei Israel hjulpet små og store grupper av bnei menashe med å gjøre aliyah. Hjelpen inkluderer blant annet finansiering av reise- og boutgifter, undervisning i ortodoks jødedom, språkopplæring, utflukter til viktige jødiske historiske steder og praktisk hjelp til bosetting. I tillegg har Shavei Israel spilt en sentral rolle i konstruksjonen av den jødiske legitimeringsmyten for prosjektet.

\section{Den jødiske legitimeringsmyten}

Bilder og filmopptak av bnei menashe som ankommer Israel, viser gjerne entusiastiske menn, kvinner og barn som verbalt og ikkeverbalt uttrykker stor glede over endelig å «komme hjem»; gjerne syngende; gjerne viftende med israelske plastikkflagg som de har fått utdelt av Shavei Israel. ${ }^{13}$ For tilheng- erne av migrasjonsprosjektet er det åpenbart viktig å fremstille hver gruppes ankomst som en gledelig og etterlengtet begivenhet. Eller som Freund selv har uttrykt det: "It is a miracle of biblical and historic proportions, and we are witnessing the words of the Prophets come to life before our very eyes. $1^{14}$

To år etter opprettelsen av staten Israel (1948) kom Loven om tilbakevending, som hadde som formål å sikre en ubegrenset jødisk migrasjon til Israel. Migrasjon til Palestina har aldri har vært forbudt for jøder, og jøder har bosatt seg i det hellige land til alle tider. Loven om tilbakevending slo imidlertid fast at alle jøder, med deres ektefeller, barn og barnebarn, har legitim rett til å komme til Israel. Loven bygger på definisjoner i Halakhá (jødisk lov) om hvem som er jøde. Her regnes en person

\section{Medlemmene av bnei menashe knytter sin identitet til myten om Israels ti tapte stammer.}

som jødisk dersom han/hun er født av en jødisk mor eller har konvertert til jødedommen. Etterkommere av Israels tapte stammer regnes dog ikke som jøder i henhold til Halakhá, og er derfor ikke berettiget aliyah med mindre de konverterer.

Blant israelske politikere har immigrasjonen av indere vært omstridt. I 2003 ble prosjektet stanset av innenriksminister Poraz. Han var ikke overbevist om indernes jødiske identitet, og hevdet de var økonomiske lykkejegere som i sin tur ble brukt av Shavei Israel og tilsvarende grupper for å øke den jødiske befolkningen i omstridte områder. ${ }^{15}$ Mye takket være Freunds lobbyvirksomhet åpnet israelske myndigheter i 2005 for at større grupper av bnei 
menashe kunne gjøre aliyah. ${ }^{16}$ Beslutningen var mulig ettersom sjefsrabbinatet ${ }^{17}$ samme år offisielt hadde anerkjent bnei menashe som etterkommere av Israels ti tapte stammer. ${ }^{18}$ For å bli regnet som jøder i dag, måtte inderne likevel gjennom en formell konverteringsprosess. Som konvertitter fikk de rett til å immigrere under Israels lov om tilbakevending.

Sammen med Shavei Israel begynte rabbinatet å gjennomføre formell konvertering av medlemmene av bnei menashe i India. Kun noen få hundre rakk imidlertid å immigrere under Loven om tilbakevending før israelske myndigheter igjen stanset prosjektet i november 2005. Denne gangen var årsaken en diplomatisk krise med indiske myndigheter, som hadde uttrykt sterk misnøye med rabbinernes misjonsaktivitet overfor indiske borgere. ${ }^{19}$ Rabbinerne ble trukket ut av India, og konverteringen av bnei menashe ble flyttet til Nepal.

I 2007 hjalp Shavei Israel 200 medlemmer av bnei menashe til Israel. Så ble prosjektet igjen stanset av myndighetene. Det ble nå stilt spørsmålstegn ved konverteringspraksisen. Et sentralt argument var at jødedommen ikke er misjonerende. Rabbinatets konverteringsaktivitet ble derfor innstilt slik at myndighetene kunne avgjøre hvordan de skulle forholde seg til medlemmer av bnei menashe som ennå ikke hadde konvertert formelt. ${ }^{20}$

De påfølgende årene drev Freund og andre støttespillere intens lobbyvirksomhet. Det virket. I oktober 2012 vedtok den israelske regjeringen enstemmig en resolusjon som tillot 274 indere å gjøre aliyah. ${ }^{21}$ I sin faste spalte i The Jerusalem Post kommenterte Freund: «I prefer to view it as Divine providence, for G-d's directive to Abraham is one that echoes down across the generations, calling out to all the people of Israel to make their way home to
Zion. And now, at last, after 2,700 years, Manasseh's children will finally be able to do so. $1^{22}$ Tatt i betraktning all uenighet knyttet til migrasjonen av bnei menashe til Israel, blir den jødiske myten svært viktig. Ikke bare utgjør den en rammefortelling som bnei menashe skriver sin identitetshistorie inn i. Den står også sentralt i legitimeringen av migrasjonsprosjektet, både overfor israelske myndigheter og jøder i inn- og utland, samt overfor ikke-jødiske støttespillere.

I tillegg til stadige utsagn om bnei menashes «jødiske identitet» og deres angivelige bevissthet om dette gjennom "2700 år i eksil», bærer fremstillingen av myten preg av den

\section{Den jødiske legitimeringsmyten, sammen} med visuelle symboler som flagg og ritualer, bygger opp om indernes identitetsforståelse.

kritikk som er blitt rettet mot prosjektet. For eksempel blir påstander om at inderne er lykkejegere, eller utgjør en økonomisk byrde for Israel, imøtegått med bemerkninger om at de er vel integrerte, utdannete, hardt arbeidende og frivillige i hæren - kort sagt et viktig bidrag til nasjonen. ${ }^{23}$ Den jødiske legitimeringsmyten, sammen med visuelle symboler som flagg og ritualer, bygger opp om indernes identitetsforståelse. I tillegg er den viktig for bnei menashes rolle i den kristensionistiske frelsesmyten.

\section{Kristensionistenes frelsesmyte}

Blant kristne er det særlig evangelikalske kristensionister som bidrar til å støtte og fremme migrasjonen av indere til Israel. I likhet med bnei menashes identitesmyte og den jødiske legitimeringsmyten, involverer også kristen- 
sionistenes myte tro på en bokstavelig oppfyllelse av gammeltestamentlige profetier om Israels gjenopprettelse, men nå er disse satt sammen med nyere teologiske teorier. Her anses nemlig tilbakeføringen som nødvendig for verdens frelse.

Den kristensionistiske frelsesmyten har sine røtter i 1800-tallets endetidsforkynnelse i Nord-Amerika. Sentralt stod ideen om et tusenårig fredsrike på jorden (eng. the Millennium $^{24}$ ). Fra midten av århundret var det dominerende synet at Jesu gjenkomst ville finne sted før dette tusenårsriket begynte. Mens denne oppfatningen hadde gamle historiske røtter, fant en ny versjon av læren veien til Amerika på 1860-tallet via irske John Nelson Darbys teori om dispensasjonalisme. ${ }^{25}$ Det er videreføringer av denne teorien som i stor grad ligger til grunn for evangelikalske kristnes engasjement for å forsvare staten Israel og hjelpe kjente og nyoppdagede jøder hjem. ${ }^{26}$

Ifølge Darby var historien inndelt i ulike tidsepoker, såkalte dispensations. Hver epoke fulgte et guddommelig fastlagt skjema som ble avsluttet med en dom, slik som syndfloden i 1 . Mosebok. Den nåværende tidsepoken var kjennetegnet av økende frafall i de institusjonelle kirkene og forringelse av samfunnet. Darby mente de sanne kristne måtte ta avstand fra dette og vente passivt på Jesu hemmelige gjenkomst, da de ville bli «henrykket» til himmelen. Resten av menneskeheten ville da oppleve syv år med trengsel før Jesus kom tilbake, sammen med de frelste, og etablere tusenårsriket, sentrert rundt Israel, det hellige land. ${ }^{27}$

Darbys teori fikk tilslutning blant protestanter på tvers av denominasjonene. ${ }^{28}$ På 1900tallet ble synet utbredt takket være The Scofield Reference Bible (1909), en studiebibel med dispensjonalistiske kommentarer, solgt i millionopplag. Her ble det blant annet hevdet at de ti tapte stammene, som er skjult i verden, sammen med jødene skal forenes til én nasjon i Palestina. ${ }^{29}$ Her finner vi også et teologisk grunnlag for den sterke evangelikalske politiske støtten til Israel: "It has invariably fared ill with the people who have persecuted the Jew - well with those who have protected him. The future will still more remarkably prove this principle. ${ }^{30}$

Den dispensasjonalistiske teologien spredde seg raskt til evangelikalske menigheter rundt om i usA. Noen forsøkte å påvirke amerikanske presidenter til å opprette en jødisk stat i Palestina, men bevegelsen forholdt seg i stor grad passiv for den jødiske sak. Likevel fulgte de med stor interesse med på opprettelsen av Israel i 1948 og på bølgene av jøder som bosatte seg der, og de tolket dette i et profetisk lys. ${ }^{31}$

På 1970- og 1980-tallet ble den kristensionistiske bevegelsen politisk aktiv. Mentalitetsendringen skjedde i lys av seksdagerskrigen i 1967 da kristensionistene observerte at hendelser de trodde ville skje etter "henrykkelsen" til himmelen, ble oppfylt under krigen: Israels erobring av Gaza, Vestbredden, Golan-høydene og Øst-Jerusalem ble tolket som et tegn på at Gud hadde vært på Israels side under krigen mot Egypt, Jordan og Syria. ${ }^{32}$ Med Guds «inngripen» under krigen fryktet kristensionistene Guds vrede over USA dersom ikke nasjonen vendte om fra sitt moralske frafall. Gradvis mobiliserte kristensionistene for å få Amerika tilbake til Cud, og de begynte å anse seg selv som aktive aktører $\mathrm{i}$ "Guds forsynte plan». ${ }^{33}$

Den dispensasjonalistiske teologien ble popularisert av kristensionistiske forfattere som Hal Lindsey og Tim LaHaye, som begge skrev fiksjonsromaner om endetiden. Utover 1980-tallet kom teleevangelister som nådde millioner av amerikanske kristne med sitt apokalyptiske språkbruk. Kristne moralforeninger og lobbyorganisasjoner ble opprettet for å føre usA tilbake til Gud, og støtte til Israel 
ble en av hovedbeskjeftigelsene til mange av disse organisasjonene. Flere av de ledende skikkelsene innenfor miljøet, som Jerry Falwell og Billy Graham, har hatt tette forbindelser til israelske statsledere. ${ }^{34}$

Denne mobiliseringen av Israel-vennlige kristne er noe av forklaringen på usAs politiske

ळo
Kristensionistene mener at Jesu annet
komme først vil finne sted når de fleste jøder
har vendt tilbake til Israel.
\&

støtte til Israel. Støtten til Israel utspiller seg på alt fra grasrotnivå til det politiske toppsjiktet. ${ }^{35}$ Kristensionistiske organisasjoner har siden blitt opprettet verden over, også i Israel, hvor de har støttet landet økonomisk og politisk. Et av kristensionistenes mest iøynefallende støtteprosjekter er deres aliyaharbeid. Kristensionistene finansierer blant annet flyreisene til jøder som ønsker å immigrere til Israel. Uten deres massive pengestøtte ville neppe folkegrupper som bnei menashe hatt mulighet til å gjøre aliyah .

Ettersom kristensionistene mener at Jesu annet komme først vil finne sted når de fleste jøder, inkludert de "tapte stammene», har vendt tilbake til Israel, ønsker disse kristne å bidra til denne tilbakevendingen. Dette bidraget mener de er profetert i Bibelen der gammeltestamentlige forfattere har skrevet om «folkeslagene» som Gud pålegger å støtte og hjelpe Israel til å gjenoppstå som et kongerike. ${ }^{36}$ Det legges dessuten stor vekt på hvordan politiske begivenheter oppfyller løftene fra Bibelen om at Cuds folk skal samles og nasjonen gjenopprettes. ${ }^{37}$

Kristensionistiske organisasjoner, som Den internasjonale kristne ambassade Jerusalem,
Christians for Israel, Ebenezer Operation Exodus og International Fellowship of Christians and Jews, jobber med å oppfordre jøder i diasporaen til å migrere til Israel. I tillegg til at de anser jødenes tilbakevending som sentral for endetiden og Jesu gjenkomst, ønsker mange kristensionister å gjøre opp for århundrer med jødeforfølgelse og fremhever gjerne humanitære motiver. Flere hundre tusen jøder har immigrert til Israel i regi av kristensionistenes bidrag. Den Internasjonale Kristne Ambassade Jerusalem har siden 2012 vært en av de viktigste organisasjonene som støtter "hjemkomsten» av bnei menashe. Støtten kan ses på som todelt: Det økonomiske bidraget muliggjør immigrasjonen, mens den ideologiske støtten bygger opp om mytene og utbredelsen av dem.

\section{Mytenes inntog i politikken}

Myten om de ti tapte stammer har fascinert mange gjennom historien, og det har florert med teorier om hva som kan ha skjedd med dem. Både jødiske og protestantiske teologer har argumentert for at stammene har overlevd som selvstendige grupper med en israelittisk identitet. Flere har også hevdet at de har funnet disse stammene, blant annet basert på studier av lokale dialekter. Stammene som er blitt identifisert, har gjerne vært etniske minoriteter og urbefolkning, som for eksempel indianerne i Amerika, etniske stammer i Kaukasia og tibetanere. Men også det britiske kongehus har blitt inkludert i teorien. Teologene har vektlagt de hellige skriftenes profetiske signifikans, som tolkes dit hen at stammene en dag skal vende tilbake til Israel og forenes med det jødiske folk. ${ }^{38}$

Ideen om at de tapte stammene har overlevd som en israelittisk entitet er altså ikke ny. Det som er nytt i vår tid, er at etniske minoriteter selv har omfavnet denne identiteten og hevder 
sin rett til å immigrere til Israel. Her får de stor støtte av jødiske og kristne interessegrupper. Som følge av interessegruppenes virksomhet, har mytene skiftet arena. Fra å være et tema som tradisjonelt har opptatt språkforskere og teologer, er det nå blitt en problemstilling for politikere. Vi ser en sammenblanding av sekulære og religiøse metoder og argumenter som også viser seg på statlig nivå. Når israelske myndigheter tillater grupper som bnei menashe å gjøre aliyah, kommuniserer det at de anerkjenner mytene.

De første immigrantene av bnei menashestammen ble bosatt blant annet på Vestbredden. Strategien bidro til å øke andelen jøder på områder palestinere gjør krav på som sine. Shavei Israel har imidlertid hevdet at denne bosettingen av nyankomne indere ikke var gjort av politiske grunner, men økonomiske: "The settlements are the only communities willing to host the Indian settlers, who are getting no financial support from the government, " har Freund uttalt. ${ }^{39}$ I senere tid har medlemmer av bnei menashe blitt bosatt på Golan-høydene, som ble annektert av Israel i 1981. De første tre månedene tilbringer de nyankomne nå i den nordisraelske byen Kfar Hasidim, et opphold som finansieres av den israelske stat og Shavei Israel - og dermed indirekte av kristensionistiske organisasjoner. ${ }^{\circ 0}$ Bosetting i omstridte områder kan derfor ikke lenger forsvares som en nødvendighet ut fra mangel på økonomisk støtte.

Sommeren 2015 kom de første 80 av 1000 nye indere som israelske myndigheter har innvilget innreise og statsborgerskap. På flyplassen ble de ønsket velkommen av nåværende innenriksminister Silvan Shalom. Til den israelske avisen Haaretz uttalte ministeren: "This is hugely exciting, bringing another group of Bnei Menashe. [...] They're returning to Israel after thousands of years, they're also returning to Judaism».41 En slik kommentar fra en statlig embetsperson, der migrasjonen fremstilles som en tilbakevending, bidrar til å bekrefte myten om bnei menashes identitet. Vi kan alltids undres hvordan innenriksministeren ville forsvart den indiske immigrasjonen dersom organisasjoner som Shavei Israel ikke hadde tilpasset og spredd den jødiske legitimeringsmyten?

I ytterste konsekvens kan de tre mytene sees på som et strategisk virkemiddel i Israels befolkningskamp for å beholde nasjonens jødiske karakter. Bnei menashe fungerer uansett som et nyttig politisk verktøy for jødiske sionister. Cruppen fremstår som hardtarbeidende og sterkt patriotisk overfor Israel, og de synes å ha en genuin tro på at de virkelig er etterkommerne av Manasse-stammen som endelig er kommet hjem.

\section{Konklusjon}

Det er så langt gjort lite forskning på bnei menashe. Vi vet derfor lite om deres individuelle motiver og holdninger, hvordan de opplever migrasjonen og det nye livet i Israel, eller hvordan de stiller seg til den politiske situasjonen i Israel og den spesifikke problematikken knyttet til bosettingsområdene. I denne artikkelen har vi imidlertid sett nærmere på de tre mytene som har gjort deres migrasjon til Israel mulig.

For det første har bnei menashes egen identitetsmyte ført til livsstilsendringer og en vilje til å migrere, som har knyttet dem til Israel og det jødiske folk. De rundt 10 ooo inderne som så langt har sluttet seg til myten, synes oppriktig å se sin identitet $i$ lys av de ti tapte stammene - et bilde som forsterkes av virksomheten til jødiske organisasjoner som Shavei Israel og ulike kristensionistiske interessegrupper. 
Den jødiske legitimeringsmyten fremstår som den mest sentrale. Ikke bare påvirker den indernes identitetsforståelse og andre sionisters oppfatning av dem. Den er også et vesentlig argument på den politiske kamparenaen som omhandler bosettingsområder. For organisasjoner som Shavei Israel handler det ikke bare om 10 ooo indere, men om migrasjon av «skjulte jøder» fra en rekke ulike folkeslag. Mens argumentene for valg av bosettingssted ofte er pragmatiske, legges det likevel ikke skjul på at tiltaket sikter mot å holde omstridte territorier «jødiske». Legitimeringsmytens betydning kan ikke betviles - for hva ville grupper som bnei menashe vært i Israel om det ikke hadde vært for den?

Den jødiske legitimeringsmyten er også sentral for kristensionistenes engasjement for å hjelpe inderne til Israel. Legitimeringsmyten knytter bnei menashes identitetsmyte sammen med den kristensionistiske frelsesmyten, som pålegger de kristne å gjøre sitt for å føre etterkommerne av alle Israels stammer tilbake til deres opprinnelige landområder i Midtøsten. Den økonomiske støtten som kristensionistene bidrar med, er på sin side en forutsetning for at migrasjonsprosjektet kan gjennomføres. I tillegg bidrar de med effektiv lobbyvirksomhet i store internasjonale organer, som FN og EU. Mens kristensionistenes støtte til Israels lenge har vært omdiskutert blant jøder, er det klart at de gjennom legitimeringsmyten har fått en instrumentell rolle i dette politiske spillet.

Det er for øvrig interessant at ideen om en jødisk identitet oppstod blant stammefolkene i Nordøst-India på 1950-tallet, noen få år etter at den israelske stat ble opprettet (1948) og Loven om tilbakevending var blitt vedtatt for å sikre ubegrenset jødisk migrasjon til Israel (1950). Vi kan derfor spørre om bnei menashe noen gang ville migrert til Midtøsten om ikke staten Israel var blitt opprettet?
Mens inderne genuint synes å tro at de vender hjem til sine forfedres lovede land, og kristensionistene like genuint synes å tro at de bidrar til å frelse verden, er det den jødiske legitimeringsmyten som i størst grad ser ut til å være en politisk konstruksjon. Alt dette gjør at de 10 ooo inderne som nå utgjør bnei menashe, beveger seg mellom ulike landskaper. Ikke bare forflytter de seg fra ett geografisk område til et annet, men de beveger seg også i det mer utydelig avgrensede landskapet som her eksisterer mellom myter og politikk.

$$
\cdot f \cdot
$$

1 Rabinowitz, G.: "Israeli 'Lost Tribes' Living in W. Bank», Shavei Israel, 24.12.2003. http://www.shavei.org/com munities/bnei_menashe/articles-bnei_menashe/israelilost-tribes-living-in-w-bank/?lang=en (oppsøkt 05.08.15).

2 "'Lost' Indian Jews Come to Israel Despite Skepticism Over Ties to Faith", Haaretz, 20.10.2013. http://www. haaretz. com/jewish-world/jewish-world-news/1.553350 (oppsøkt 20.07.15); Cook, J.: "Lost tribe' on Fast Track to Israel: Settlers seek to recruit Indian immigrants", Global Research, 28.01.2010. http://www.globalresearch.ca/lost-tribe-onfast-track-to-israel/17254 (oppsøkt 20.07.15).

3 Rabinowitz 2003.

4 De største stammene som medlemmene av bnei menashe kommer fra, er kuki og mizu, som til sammen har over 1,5 mill. medlemmer.

5 Epstein, S.: "A Long-Lost Tribe is Ready to Come Home», BneiMenashe.com. http://www.bneimenashe.com/history. html (oppsøkt 05.08.15); "Bnei Menashe», BneiMenashe.com http://www.bneimenashe.com/ (oppsøkt 05.08.15); "Jewish tribe in India celebrates pre-Passover seder, hoping next year will be in Jerusalem", The Jerusalem Post, 02.04.2015. http://www.jpost.com/Diaspora/Jewishtribe-in-India-celebrates-pre-Passover-seder-hoping-nextyear-will-be-in-Jerusalem-395974 (oppsøkt 05.05.15); Zote, M: "Heaven in Hell: a paradox." India International Centre Quarterly, Vol. 32, No. 2/3, 2005, s. 203-207; Cook 2010.

6 Epstein n.d.

7 Kelly, L.: "The long path from India to Israel», The Jerusalem Post, 19.07.2015. http://www.jpost.com/Diaspora/Thelong-path-from-India-to-Israel-409261 (oppsøkt 05.08.15).

8 Lyman, S. M.: "The lost tribes of Israel as a problem for History and Sociology». International Journal of Politics, Culture and Society, Vol. 12, No 1, 1998. s. 10; Groth, Bente: Jødedommen. Oslo: Pax Forlag 200, s. 41.

9 Lyman 1998 , s. 8.

10 Lyman 1998, s. 10.

11 Epstein, S.: "A Long-Lost Tribe is Ready to Come Home", BneiMenashe.com. http://www.bneimenashe.com/history. html (oppsøkt 05.08.15). 
12 Kelly 2015; "How to Help the Bnei Menashe», BneiMenashe.com. http://www.bneimenashe.com/help. html (oppsøkt 05.08.15).

13 Kelly 2015. Se også f.eks. https://www.youtube.com/user/ ShaveiIsrael.

14 Freund, M.: "Homecoming for a Lost Tribe of Israel», The Jerusalem Post, 10.11.2012. http://www.jpost.com/ Opinion/Columnists/Homecoming-for-a-Lost-Tribe-ofIsrael (oppsøkt 05.08.15).

15 Wagner, M.: "Bnei Menashe conversions halted", The Jerusalem Post, 09.11.2005. http://www.jpost.com/JewishWorld/Jewish-News/Bnei-Menashe-conversions-halted; Krieger, H.: "Bnei Menashe aliya, conversions halted pending government review», The Jerusalem Post, 02.07.2006. http://www.jpost.com/Israel/Bnei-Menashealiya-conversions-halted-pending-government-review (oppsøkt 05.08.15).

16 Kelly 2015.

17 Det israelske sjefsrabbinatet er øverste religiøse myndighet i Israel. Rabbinatet besvarer blant annet spørsmål om Halakhá fra jødiske offentlige organer i diaspora.

18 Krieger 2006.

19 Wagner 2005; Krieger 2006; Freund, M.: "'Let my people in!'», The Jerusalem Post, o1.11.2005: http://www.jpost.com/ Features/Let-my-people-in (oppsøkt 05.08.15).

20 Krieger 2006

21 Freund, M.: "A 'Lost Tribe' that is lost no more", The Jerusalem Post, 26.12.2012. http://www.jpost.com/ Opinion/Columnists/A-Lost-Tribe-that-is-lost-no-more (oppsøkt 05.08.15).

22 Freund 2012

23 Se f.eks. Freund: 2012; Freund, M.: "Fundamentally Freund: Operation Menashe: A lost tribe's journey home to Zion", The Jerusalem Post, 30.12.2013. http://www. jpost.com/Opinion/Columnists/Fundamentally-FreundOperation-Menashe-A-lost-tribes-journey-home-to-Zion336603 (oppsøkt 05.08.15).

24 Begrepet "millennium», eller "tusenårsrike» forekommer ikke i Bibelen, men en periode på 1000 år nevnes flere ganger i Åpenbaringsbokens 20. kapittel. I den aktuelle myten tolkes dette som opprettelsen av et jordisk rike med fred og velstand som varer i 1000 år.

25 Trollinger, W.V.: "Protestantism and Fundamentalism», i A. E. McGrath og D. C. Marks (red.), The Blackwell Companion to Protestantism. Malden (MA): Blackwell Publishing (2004), s. 346; Woodberry, R.D. and C.S. Smith: "Fundamentalism et al: Conservative Protestants in America», Annual Review of Sociology, Vol. 24, (1998), s. 27; Harding, S.: "Imagining the Last Days: The Politics of Apocalyptic Language", i M.E. Marty og R.S. Appleby (red.), Accounting for Fundamentalisms. The Dynamic Character of Movements. Chicago: The University of Chicago Press (1994), s. 57.

26 Det finnes mange grunner og argumenter for å støtte Israel. Vårt fokus er imidlertid på myten som ligger til grunn for kristensionistenes engasjement i det indiske migrasjonsprosjektet, og vi ønsker å vise hvordan teologien her blir brukt i en sosiopolitisk kontekst.

27 Trollinger 2004, s. 346; Ellingsen, M.: The Evangelical Movement: Growth, Impact, Controversy, Dialog. Minneapolis: Augsburg Publishing House (1988), s. 62-65.
28 Ellingsen 1988, s. 61-65.

29 Se f.eks. Scofields kommentar til Jes. 7, 2. Tilgjengelig online: http://www.studylight.org/commentaries/srn/ view.cgi?bk=22\&ch=7.

30 Scofields kommentar til pakten med Abraham i 1. Mos. 15, 18. Tilgjengelig online: http://www.studylight.org/ commentaries/srn/view.cgi?bk $=0 \& \mathrm{ch}=15$.

31 Cohn-Sherbok. D.: The politics of apocalypse: the history and influence of Christian Zionism. Oxford: Oxford Publ. (2006), s. 111115 .

32 Ariel, Y.: "An Unexpected Alliance: Christian Zionism and Its Historical Significance." Modern Judaism. Vol. 26, no. 1, 2006, s. 81.

33 Harding 1994, s. 66.

34 Spector, S.: "Evangelicals and Israel: the story of American Christian Zionism.» Oxford: Oxford University press, 2009, S. 148 .

35 Waxman, D.: "The Jewish Diaspora and the Pro-Israel Lobby", i J. Newman og D. Peters (red.), The Routledge Handbook on the Israeli-Palestinian Conflict. New York: Routledte (2013), s. 360-364; Waxman, D. "The Israel Lobbies: A Survey of the Pro-Israel Community in the United States", Israel Studies Forum, Vol. 25, No. 1, 2010, s. 9, 15; Harding 1994, s. 57-74.

36 Se f.eks. Jes. 49, 22; Jes. 40, 1 og Jer. 16, 16.

37 Se f.eks. http://int.icej.org/media/biblical-standzionism-i

38 Bokomtale av «The Lost Tribes of Israel: The History of a Myth" av Tudor Parfitt, anmeldt av K. Nathan i Bulletin of the School of Oriental and African Studies, University of London, Vol. 66, No. 2, 2003, s. 259; Lyman 1998, s. 12-13.

39 Rabinowitz 2003.

40 Lior, I.: "Minister Shalom Pledges to Bring More Bnei Menashe and Falash Mura to Israel», Haaretz, 25.06.2015. http://www.haaretz.com/news/israel/.premium-1.663 o57?date $=1440764363593$ (oppsøkt 05.08.15).

41 Lior 2015. 